\title{
The Thinking Frames Approach: Improving High School Students' Written Explanations of Phenomena in Science
}

\author{
Felicity McLure ${ }^{1}$ D
}

Accepted: 3 February 2022 / Published online: 25 February 2022

(C) The Author(s) 2022

\begin{abstract}
Secondary school students find it difficult to write elaborated causal explanations of scientific phenomena. They frequently present their own opinions and write descriptions of their observations rather than linking observations with logical chains of causal reasoning, underpinned by a theoretical framework, to provide explanations of scientific phenomena. Science teachers also express difficulties in supporting students to develop scientific writing skills. In order to improve students' written scientific explanations, a teaching strategy known as the Thinking Frames Approach (TFA) was introduced into two Grade 9 classrooms over two years. This multidimensional conceptual change strategy makes use of the affordances of student-generated multiple representations, teacher-student questioning, and small group discussions to support students in constructing understanding and written explanations. Students are also taught to reflect on and evaluate their written explanations. Students' written responses explaining observations of scientific phenomena were collected over a nine-month period and evaluated using the analysis system for student explanations developed by de Andrade et al. (Res Sci Educ 49:787-807, 2019). A significant improvement in students' written explanations linking observations with logical chains of reasoning and scientific theories was observed over this period. The TFA provides a strategy that teachers may implement to support students in developing skills in writing explanations by providing an appropriate level of scaffolding in the writing process. An added benefit of this approach was students' increased confidence in producing written explanations.
\end{abstract}

Keywords Writing scientific explanations $\cdot$ Multiple representations $\cdot$ Scaffolding $\cdot$ Causal reasoning

\section{Introduction}

Recent education reforms have included a focus on developing literacy skills across all subject domains, including teaching students to write causal scientific explanations and present arguments in science (ACARA, 2016a, b; Council of Ministers of Education, 2013; National Research Council, 2012). Construction of scientific explanations of observed

Felicity McLure

felicity.mclure@murdoch.edu.au; felicity.mclure@cdu.edu.au

1 School of Education, Murdoch University, Perth, Australia 
phenomena is one of the core practices of scientists and hence should be an important feature of learning to think like a scientist (Zimmerman, 2007). The emphasis placed on using theoretical models to write causal explanations of scientific phenomena in some end of schooling external examinations further highlights the importance of developing these skills (Fensham \& Bellocchi, 2013). However, few strategies to guide teachers in developing students' skills to produce written explanations have been studied (Nawani et al., 2019).

Writing scientific explanations needs to be explicitly developed (McNeill et al., 2006; Osborne et al., 2004). Middle school and older students tend to make claims without using reasoning to support those claims and rarely refer to underlying theoretical models to justify explanations (Jimenez-Aleixandre et al., 2000; McNeill et al., 2006). This study investigates the efficacy of a multi-dimensional conceptual change strategy, the Thinking Frames Approach (TFA) (Newberry et al., 2011) which provides scaffolding through production of multiple representations in improving students' written causal explanations.

Multidimensional conceptual change approaches in science education are based upon the integration of epistemological, ontological, and affective frameworks for understanding how students can be guided to adopt scientific models for explanation of phenomena (Duit $\&$ Treagust, 2012). Beginning with the conceptual change model of Posner et al. (1982), a multidimensional conceptual change strategy, such as the TFA, provides cognitive conflict between the student's presently held naïve conceptions and scientific conceptions, in order to make students aware of the need to change their explanations for a particular phenomenon. Additionally, the framework theory of Vosniadou (1994) and understanding of ontological category shifts described by Chi (1992) resulted in recognition that, for conceptual change to occur, conflicts between students' underlying ontological models and scientific models must also be explicitly addressed. However, it was found that focusing on the cognitive aspects of conceptual change, without engaging affective aspects of learning, did not result in long-lasting adoption of scientific understanding and students tended to return to the prior explanations that they had held (Duit \& Treagust, 1998). Studies of Intentional Conceptual Change (Sinatra \& Pintrich, 2003) showed the importance of developing students' self-efficacy and motivation in order to engage learners and support long-term and intentional adoption of scientific understanding. The TFA is a multidimensional conceptual change approach (McLure et al., 2020c) which includes strategies to address all three of these domains of conceptual understanding in order to support students in developing scientific explanations for phenomena.

\section{What Makes a Good Scientific Explanation?}

Before discussing the elements of a good scientific explanation, it is necessary to clarify the distinction between a scientific argument and a scientific causal explanation. Although these two terms are frequently used interchangeably, Osborne and Patterson (2011) argue that these two modes differ in epistemic function: a scientific argument uses empirical evidence and counter-evidence to support or argue against a tentative claim purporting to explain observations; while a scientific explanation is a causal-mechanistic account of why a particular phenomenon occurs based on accepted theoretical models (Tang, 2016). While both scientific arguments and explanations are important features of science, and hence science education (Braaten \& Windschitl, 2011), Brigandt (2016) argues that it is important to differentiate between these two forms of writing and to ensure that both forms are developed. This paper focuses on scientific causal explanations rather than arguments, 
since limited attention has been paid to developing strategies to improve students' scientific explanations.

Gilbert et al. (2000) identified six types of explanations. The types that this paper will focus on are those that describe the properties of the materials involved in the phenomena being explained, interpret relevant models to understand these properties, and produce a causal mechanism which links the model with the observed effect (Gilbert et al., 2000). A framework developed by de Andrade et al. (2019) is used to measure causal explanation levels of students' written work. This framework is based upon two theoretical models rooted in philosophy of science: the causal model (Salmon, 1984; Woodward, 2003) which requires that a phenomenon be traced back to a series of events (based on theoretical entities or laws) and the unification model (Friedman, 1974; Kitcher, 1989) which link a number of phenomena to models to build a more comprehensive understanding of the universe.

What then makes a good scientific causal explanation? de Andrade et al. (2019) identified four elements of good scientific explanations: relevance, based on a theoretical framework, contains appropriate and explicit causal links between observations and the theoretical framework, and makes reference to microscopic, sub-microscopic, or non-visible entities and processes such as particles, energy, and forces. However, studies have shown that students frequently fail to recognize the most relevant aspects of a phenomenon (e.g., Faria et al., 2014), have difficulty linking observations that they make with an underlying theoretical scientific model (e.g., Taber \& Garcia-Franco, 2010), and struggle to represent their understanding of visible processes in terms of non-visible entities (e.g., Prain et al., 2009).

\section{Studies Focusing on the Improvement of Students' Written Explanations}

While there have been numerous studies of ways in which to support students in producing written arguments based on inquiry tasks or data, such as the Claim, Evidence, Reasoning (CER) framework (e.g., Hsu et al., 2015; McNeill et al., 2006; Yang \& Wang, 2014), there have been few studies reporting the development of strategies to support students in producing written causal explanations (Tang, 2016). Questions have been raised about the suitability of the CER framework to evaluate and support written explanations, as this framework focuses on reasoning using empirical evidence to support claims, while the focus of causal explanations is on the application of widely accepted theoretical models to provide explanations of natural phenomena (Osborne \& Patterson, 2011; Tang, 2016).

In order to help students scaffold scientific explanations, Tang (2016) identified a threecomponent construct: presenting the premise of the underlying laws/theoretical models $(\mathrm{P})$, reasoning $(\mathrm{R})$ using a series of causal statements, and a description of the outcome $(\mathrm{O})$. However, although students found the PRO scaffold helpful in organising scientific explanations, concerns were expressed over the rigidity of the structure and difficulties students found in identifying PRO in different contexts (Tang, 2016).

Although a framework for supporting students in producing causal-mechanistic written explanations in senior biology topics was described by Nawani et al. (2019) which involved an iterative process of constructing and revising an explanatory story, and then applying that explanation in other scenarios, this research did not evaluate the success of such an approach in terms of improvements in student explanations. The proposed use of the TFA in this study presents an alternative way forward for supporting students in writing elaborated causal explanations. 


\section{The Thinking Frames Approach (TFA)}

The TFA is a multidimensional conceptual change approach that engages students' interest and cognition through presentation of discrepant events, scaffolds explanation development through production of multiple representations of explanations in verbal, pictorial, and written modes, supports co-construction of understanding through small group interactions and careful questioning strategies used by the teacher, and gives opportunity for self-reflection and evaluation of explanations (McLure et al., 2020c). TFA lessons are comprised of the following elements:

1. Challenging alternative conceptions: Students are placed in small groups and are presented with a scenario designed to challenge alternative conceptions held in that topic. Following a small group discussion where they predict what would happen and why, they present ideas to the class. The teacher then carries out the demonstration (or describes the outcome of a scenario) and students produce an explanation which is consistent with observations. These revised explanations are then presented to the class.

2. Encouraging elaborated construction of verbal explanations: Socratic questioning by the teacher supports students in elaborating explanations, linking explanations to observations and the ontological model (e.g., the particle model of matter or theories of heat transfer).

3. Explanations in pictorial and written modes: Keywords for writing explanations are identified by students. Working in the small groups, they construct individual diagrammatic explanations. Understanding is then transferred into a logical sequence of short dot points and finally, elaborated written explanation of the phenomenon are produced (Treagust et al., 2018). Production of student-generated multiple representations have been shown to motivate students to engage more fully with explanation construction and support students to adopt higher levels of explanation (Chang et al., 2016), including more frequent use of non-visible entities and causal statements (McLure et al., 2021). While students create multiple representations of their understanding, the teacher moves between groups using questioning to encourage further elaboration of ideas.

4. Engaging meta-cognition through self-evaluation: Students use a rubric, the Levels Mountain (LM) (Newberry et al., 2005), to critique and mark their own written explanations. Levels 1 and 2 of the LM describe simple and more detailed descriptions of students' observations which do not provide a causal statement. Level 3 is a simple causal explanation. Level 4 describes a more detailed explanation which includes aspects of the scientific model. A level 5 explanation includes more complex chains of reasoning linked to a scientific model.

5. Feedback from the teacher: The teacher uses the LM rubric to evaluate students' explanations. They provide specific and constructive feedback about ways in which the student may improve their explanation to meet the next level on the LM (c.f. Hattie \& Timperley, 2007).

6. Gradual building of conceptual understanding over time: A series of TFA lessons supporting students in constructing understanding of different aspects of the theoretical scientific model are designed for each topic.

\section{Research Questions}

The research questions investigate the efficacy of the TFA in developing students' written causal explanations of scientific phenomena: What evidence is there that the TFA supports students in writing scientific explanations? What are the students' perceptions of the TFA in terms of support for writing scientific explanations? 


\section{Method}

\section{Research Design}

This study was part of two-year explanatory sequential mixed-methods (Creswell, 2014) research investigating the effects of the TFA as implemented in the teaching of a variety of science topics. It presents a longitudinal explanatory case study (Yin, 2009) of students in two Grade 9 classes and their experience of the TFA over nine months as they wrote explanations of phenomena in physics, chemistry, and biology topics. Apart from some anecdotal reports of the efficacy of the TFA for improving students' written explanations, no research had been published studying the effects of the TFA on conceptual understanding and student writing prior to this study. The supportive effects of the TFA on students' conceptual understanding (McLure et al., 2020b, c, d), affective aspects of learning (McLure et al., 2020a), and benefits for inclusion of students with special educational needs (McLure, 2020) have been presented in earlier publications by the author.

\section{Context and Participants}

Research was conducted in two Grade 9 classes (15-year-old; $N=51$ ) over two consecutive years in a moderate-fee paying co-educational non-government school in Australia. Classes were of mixed ability and on average students had mid-range socio-economic status for the region, according to government statistics. The study commenced after obtaining ethics approval and informed consent from all participants and their caregivers. The teacher in both years was a teacher-researcher with 10 years' experience. Examples of written explanations under exam conditions at the end of the teaching period from a class that had not experienced the TFA were used as a comparison. Comparison was appropriate as the two Grade 9 classes had no significant differences in numeracy and literacy results as measured by $t$-test comparison of results from national standardised testing (NAPLAN).

\section{The Thinking Frames Approach Lessons}

An example of a series of TFA lessons is found in Table 1. The overall aim of these lessons was to build understanding of thermal energy (McLure et al., 2020d), what it is, how it is transferred, why some materials are poor or good conductors of thermal energy, ways that thermal energy can be transferred, and to explain why increasing thermal energy does not always lead to an increase in temperature.

\section{Data Collection}

Samples of students' written explanations from the first TFA lesson in each year provided examples of pre-intervention writing skills. In this lesson, students were asked to explain why the atomic model changed over time. After watching short videos presenting three atomic models (Dalton's, Thomson's, and Rutherford's) and evidence that changed understanding of the atom, students were asked to discuss the reasons why the atomic model had changed, present an explanation to the class, and then represent their 


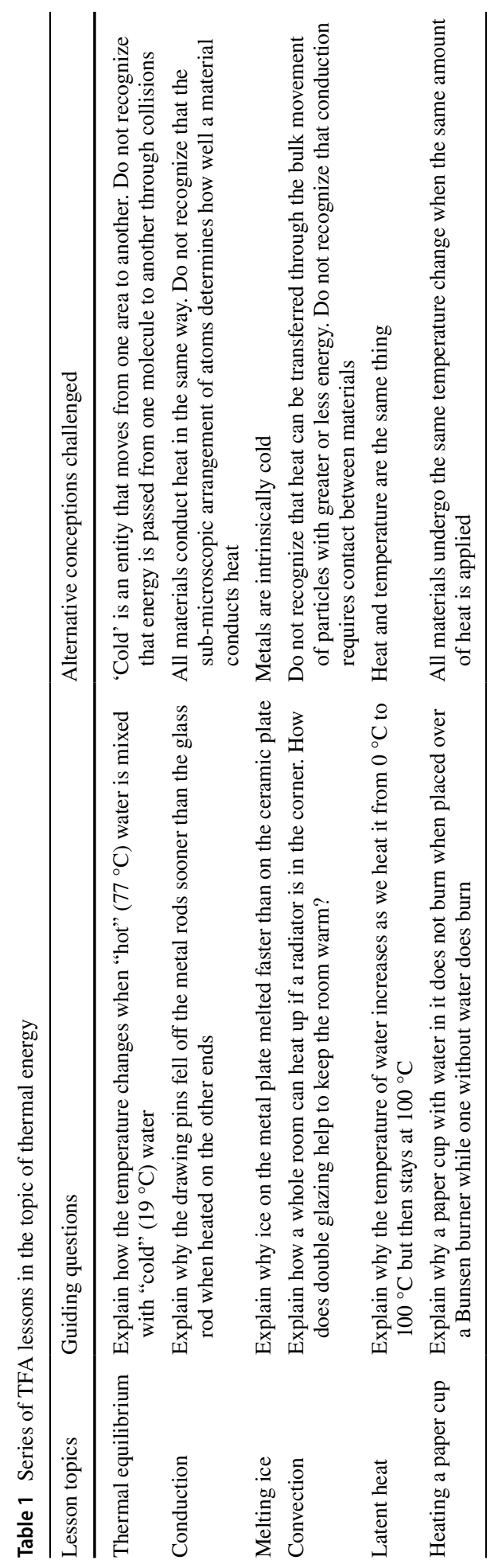


explanation through drawings, summary points, and an extended written explanation. Student worksheets were collected after this and all other TFA lessons.

Students of one Grade 9 class who learned with the TFA and a comparison class in the same year were examined ten days after the teaching cycle on thermal physics. The extended examination question was based on TFA14. Both classes had been shown this experiment. While the experimental group constructed explanations of their observations using the TFA, the comparison group had developed explanations with the teacher without the use of the TFA. This gave the opportunity to compare independently produced written explanations from a non-treatment and treatment group.

A purposive sample of students $(n=27)$ representing all achievement levels were interviewed using a semi-structured interview protocol to probe student perceptions of the TFA at the end of the year. Students were asked to describe their feelings about writing scientific explanations before and after learning with the TFA.

\section{Analysis of Written Explanations}

A generalised analysis framework for scientific explanations was employed to evaluate students' written explanations (de Andrade et al., 2019). Written explanations were compared where the same students were present in both lessons and the majority of students were present. Mean and standard deviations were determined for each lesson; two-tailed paired $t$-tests, 95\% confidence intervals, and Cohen effect sizes were calculated between writing from the first TFA lesson and a final TFA lessons to determine the degree of change in level of written explanations over the period of teaching. Analyses using the de Andrade et al. (2019) framework were carried out twice, and cross checks were made to compare all responses that were deemed to be at the same level to ensure consistency in marking. Responses under exam conditions were marked by the author and these marks were checked and corroborated by a second teacher.

\section{Explanation Analysis Using the Framework of de Andrade et al. (2019)}

Students' written explanations were evaluated at the end of each lesson using the Levels Mountain (LM) rubric (Newberry et al., 2005) described above. The analysis rubric for scientific explanations developed by de Andrade et al. (2019) (Fig. 1) has similar levels to those found in the LM framework but clarifies and elaborates those levels. For this reason, this rubric was used post hoc to analyse students' written explanations and compare written explanation levels over a nine-month period. Levels within this framework were given values of 1 (non-explanation) through to 6 (complex explanation).

\section{Results}

\section{Development of Students' Written Explanations}

Students in two Grade 9 classes over two consecutive years learned a variety of topics using the TFA: atomic structure and bonding, ecosystems, thermal energy, and electricity. To analyse the development of students' written explanations across that period, data from 


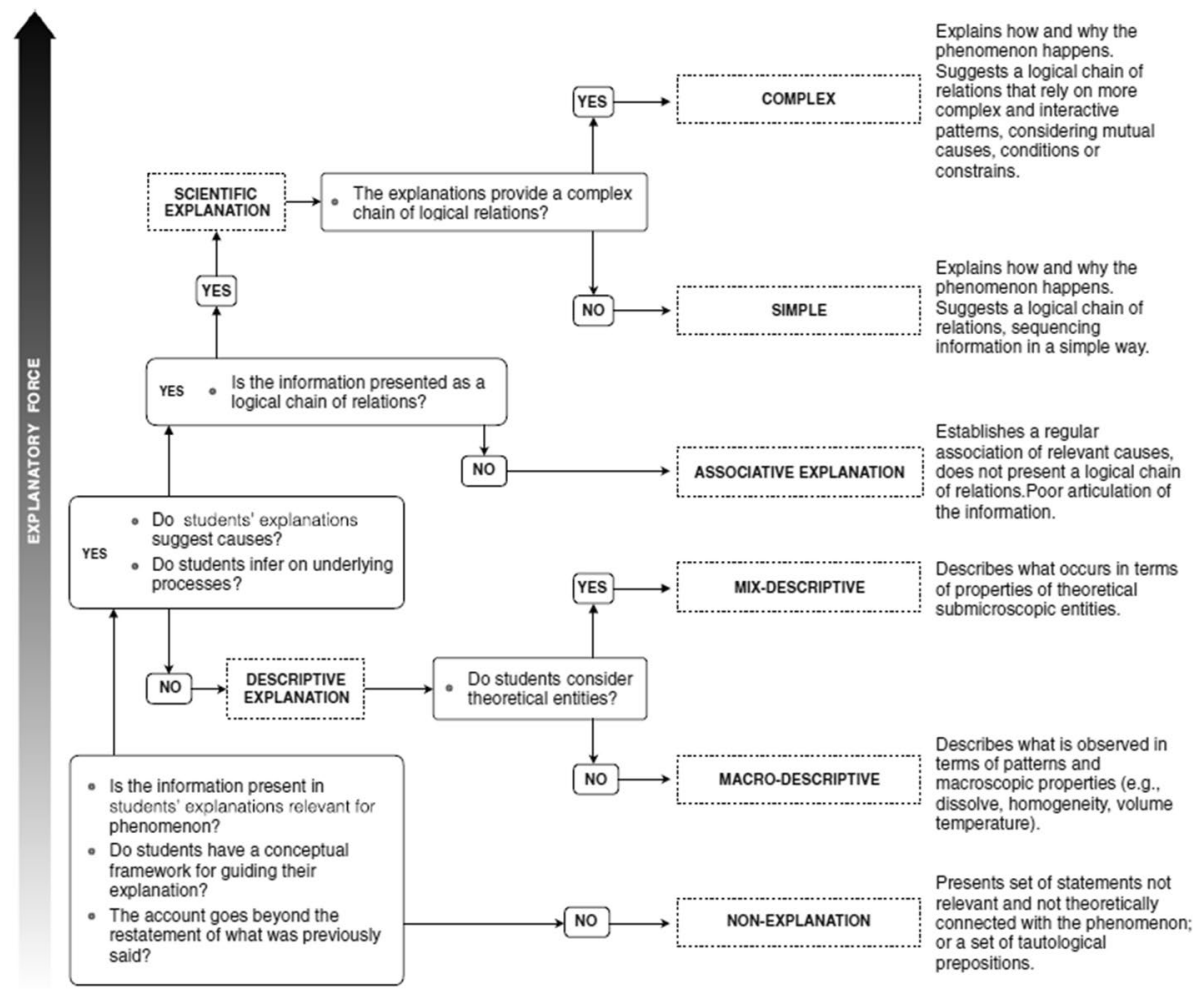

Fig. 1 de Andrade et al.'s (2019) framework for analysis of written explanations reproduced with permission

TFA lessons where the same students were present $(n=26)$ were analysed. Mean explanation levels, as determined using the de Andrade et al. (2019) framework for written explanations, are presented in Table 2. Grade 9 students began the year by writing descriptions of their observations rather than causal explanations of phenomena (TFA1, $M<4$ ).

Students found certain topics easier to write explanations about. For example, most students wrote elaborated causal explanations using scientific language to explain why scientists believe that simple organisms like jellyfish will take over the oceans (TFA6, $M=4.38$ ) after watching a documentary about the effects of overfishing. Many of the concepts related to food chains and webs were familiar to students and involved interactions between visible entities, which may be easier for students to explain than those that require discussion of interactions on a microscopic or sub-microscopic level (Gilbert \& Treagust, 2009). The concepts within the thermal energy topic, however, were unfamiliar to students and they held many alternative conceptions about thermal energy at the beginning of the unit (TFA10) which resulted in a slight decrease in mean scores. However, they were mostly able to write elaborated causal explanations for thermal physics phenomena presented in TFA 10,12, and 14. The statistically significant improvement in ability to link cause and effect and use scientific language over the period of implementation can be seen when comparing the mean level for TFA1 $(M=3.27)$ with that of TFA14 $(M=4.93)$. The effect size for this improvement was very high at 1.87 . A plateau effect was seen towards the end 


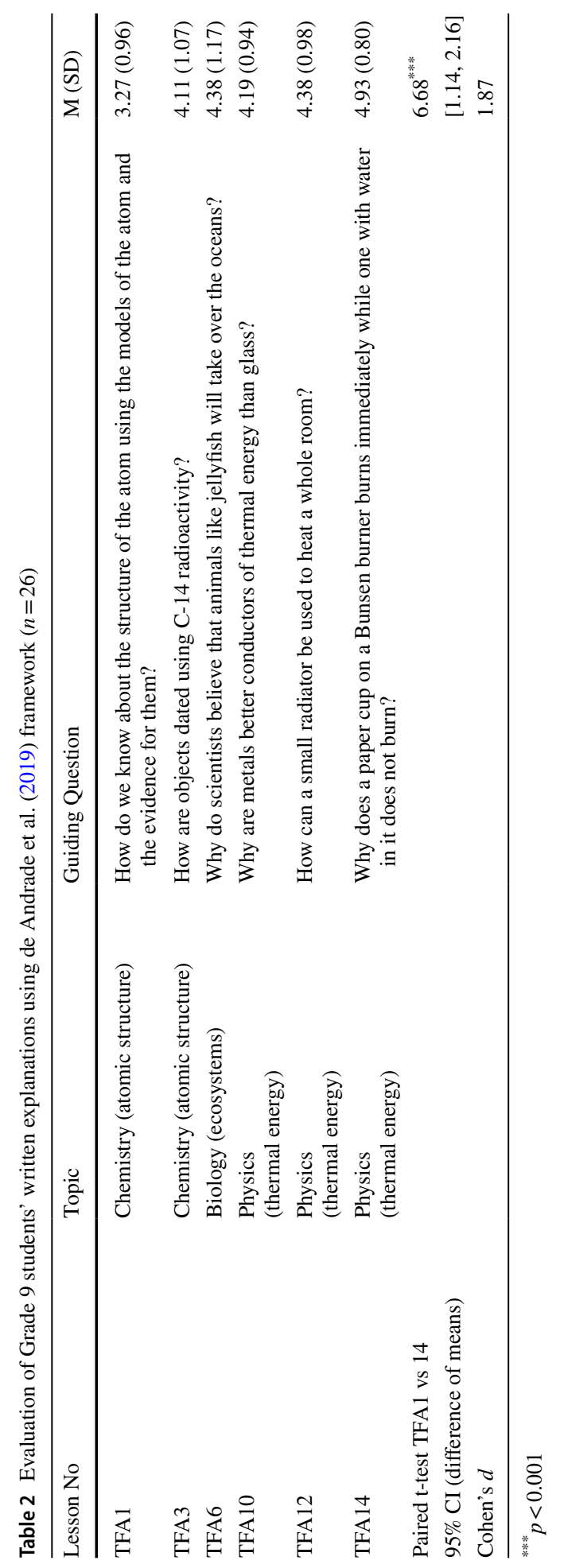


of the year, as students became aware of the elements required in writing elaborated causal explanations.

Examples of written explanations at each de Andrade et al. (2019) level are given in Table 3.

To compare the change between TFA 1 and TFA14 for all Grade 9 students, a $t$-test comparison was made with data from 46 students who completed both lessons (Table 4). The analysis reveals a statistically significant improvement in production of causal explanations and a very large Cohen effect size of 1.51 (Table 4). The distribution of levels of the written explanations for TFA1 and TFA14 are presented in Fig. 2. There were eight non-explanations in response to the first TFA lesson and no non-explanations in response to the 14th TFA lesson. Additionally, there were five simple scientific explanations and no complex scientific explanations in lesson 1 while there were 16 simple and 10 complex scientific explanations given in lesson 14 .

\section{Comparison of Written Explanations in an Extended Examination Question}

The results from an extended answer question on thermal physics administered under exam conditions can be seen in Table 5. Students from the TFA group had achieved a mean level of 4.44 when socially constructing explanations in the classroom. Although the mean for the same group of students when constructing explanations alone under exam conditions dropped to 4.00 (Table 5), this still showed a significantly higher number of scientific explanations when compared with the comparison group $(\mathrm{M}=2.76)$.

A comparison of the explanation levels attained by the TFA and comparison groups is found in Fig. 3. The answers given by students from the TFA group were noticeably more detailed and 10 students produced simple or complex explanations linking the scientific concepts of thermal physics with the observations in this experiment, compared to two students from the comparison group who produced simple scientific explanations. Correct use of concepts such as thermal heat capacity and understanding of latent heat of vaporisation and thermal equilibrium, while present in many written explanations of the TFA group, were absent from all of the comparison group explanations despite having learned about each of these concepts in class.

\section{Examples of Students' Written Explanations}

Over the period learning using the TFA, students' written explanations increased in the use of scientific concepts, and in explanations of observations in terms of scientific theories. TFA 14 gave opportunities for students to write explanations of questions that linked several concepts from previous lessons. Explanations that scored a level 6 were not only scientifically accurate, used appropriate vocabulary, but they were also well-organised and synthesised a variety of thermal concepts. The increased elaboration of ideas, use of causal links between observations, non-visible processes, and scientific theory, and use of scientific vocabulary in written explanations is illustrated in the writing of Willa. Willa was chosen as an example of a student who achieved average results in science prior to the study and who began with low feelings of self-efficacy as a science student. She consistently engaged with the TFA process over the year of this study and represents the many students who started the year writing simple descriptions rather than explanations and progressed to writing elaborated causal explanations. 


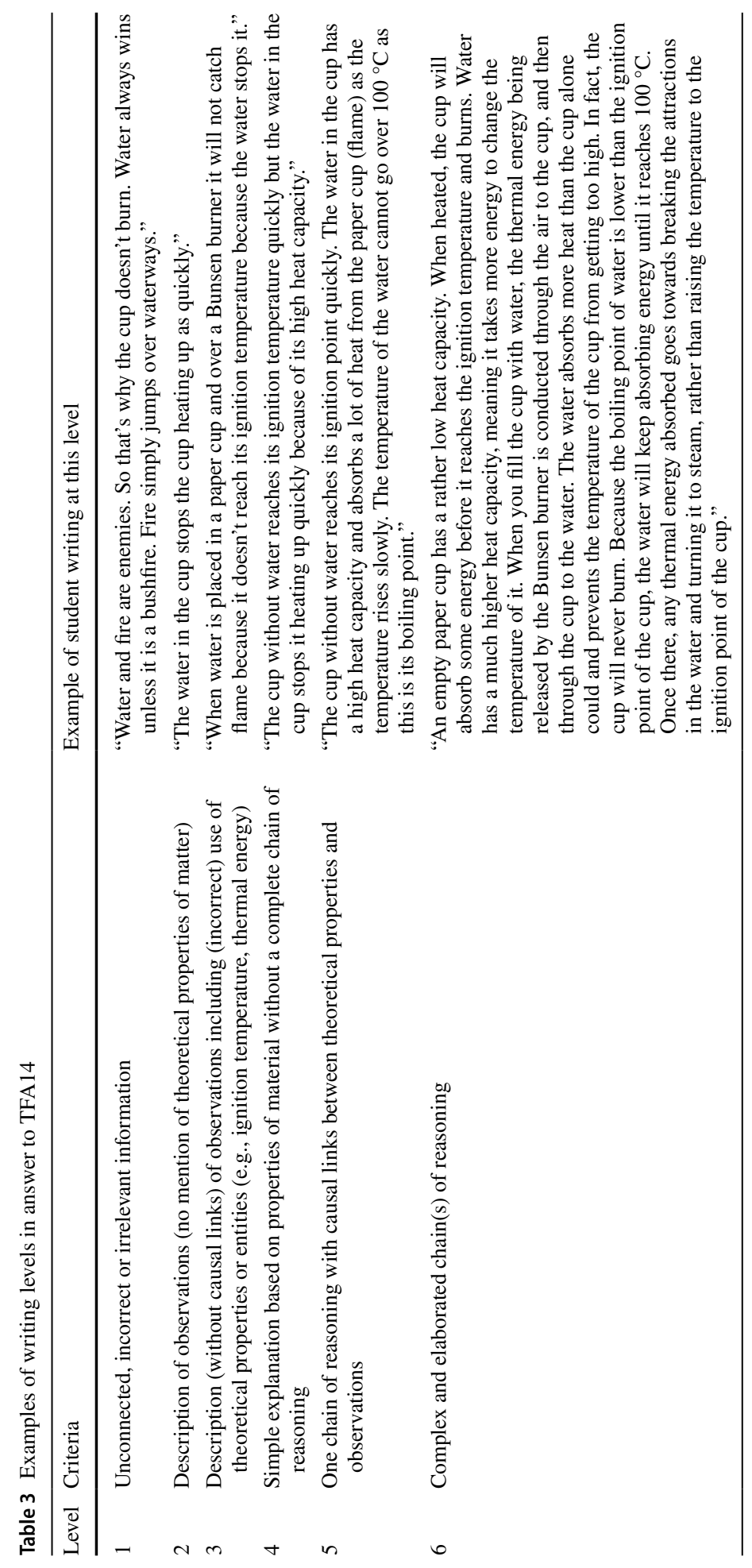


Table 4 Improvement in all Grade 9 students' written explanations using de Andrade et al.'s framework $(n=46)$

\begin{tabular}{llllll}
\hline & $\begin{array}{l}\text { TFA 1 } \\
\text { M (SD) }\end{array}$ & $\begin{array}{l}\text { TFA 14 } \\
\text { M (SD) }\end{array}$ & $\begin{array}{l}\text { Paired t-test } \\
\text { TFA1 vs 14 }\end{array}$ & 95\% CI (difference of means) & Cohen's $d$ \\
\hline Mean level & $2.98(1.22)$ & $4.65(1.00)$ & $9.37^{* * *}$ & {$[1.31,2.03]$} & 1.51 \\
\hline
\end{tabular}

${ }^{* * * *} p<0.001$

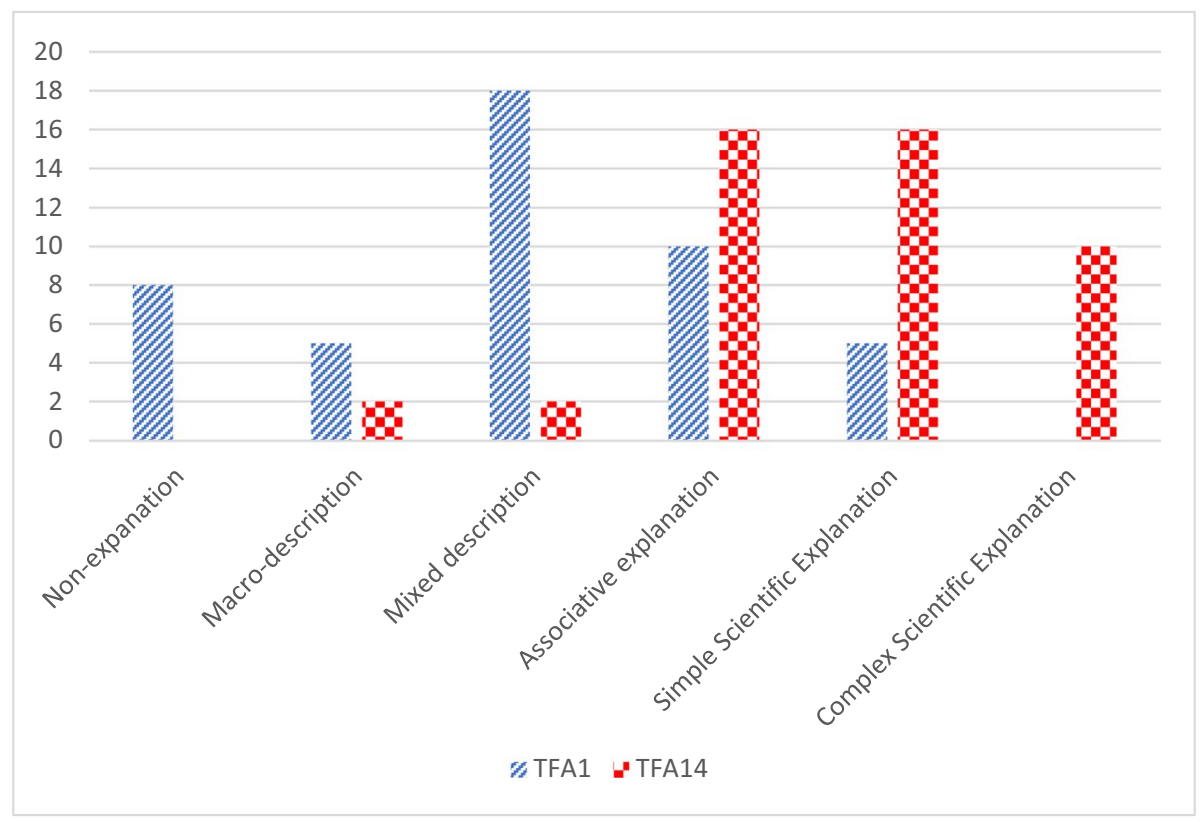

Fig. 2 Comparison of levels of written explanations for TFA1 and TFA14 $(n=46)$

At the beginning of the year, Willa's answer to TFA1 gave a description of two different models of the atom together with a description of Rutherford's experiment. This was a mixed description, based on the de Andrade et al. (2019) framework, because, although she mentioned sub-atomic particles, she did not produce any causal statements to explain why observations led to these changes in theoretical models.

Willa (TFA1): Firstly, Dalton believed that atoms were indivisible and very small but then he found that they could be split. Then Thomson's theory was that an atom was like a cake with the electrons being the pieces of fruit and the rest of the cake being positive. Finally, Rutherford conducted an experiment where he fired positively charged alpha particles at a gold sheet and recorded where they went with a sensor. Some richochetted [sic] off of the sheet but most went through to the other side.

(Mixed description, 3)

By the middle of the second semester, however, Willa was able to produce more elaborated causal explanations. Her explanation for TFA14 successfully linked the concepts of thermal energy transfer, thermal heat capacity, and latent heat of vaporisation to explain 


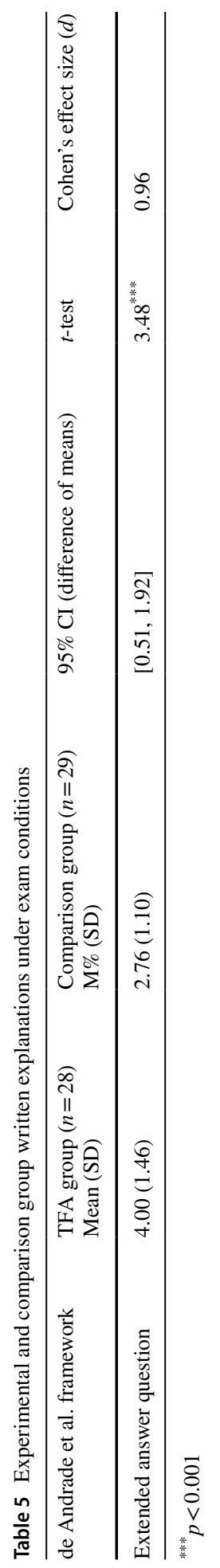




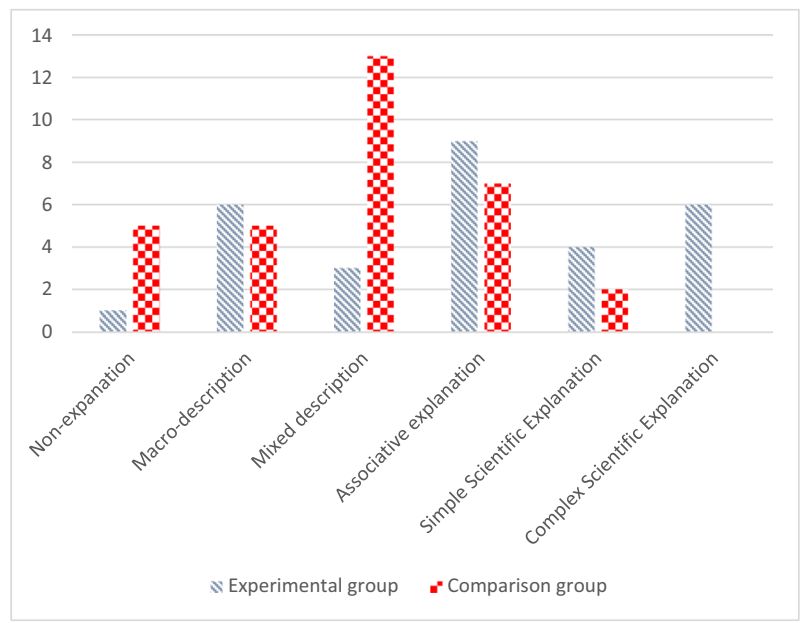

Fig. 3 Comparison of explanation levels of TFA $(n=29)$ and comparison group $(n=32)$ under exam conditions

that the cup over the Bunsen burner did not reach ignition temperature when it contained water. Although she displayed a limited understanding of thermal equilibrium, she used a complex chain of reasoning, together with correct usage of other scientific vocabulary to produce a cohesive argument. Her written explanation displays considerable conceptual growth in the topic of thermal physics.

Willa (TFA14): When a cup filled with water is heated by a Bunsen burner, thermal energy from the Bunsen burner is transferred to the paper cup through both radiation and conduction. The cup heats the water through conduction, and convection means that the water is heated [throughout]. Water has a high thermal heat capacity, and because of the water and the cup's contact thermal equilibrium keeps the cup and the water's temperature rising together slowly. When their temperature reaches $100^{\circ} \mathrm{C}$, the thermal energy is used for latent heat of vaporisation. The cup cannot light on fire because of thermal equilibrium and until the water is all evaporated the cup will not be able to reach its ignition temperature.

(Complex scientific explanation, 6)

In an interview with Willa at the end of the year she indicated that she believed that she was much more able to understand new scientific concepts, felt confident in expressing explanations in a written format, and was much more interested in Science as a whole.

Willa: With the Thinking Frames I am really confident now. I used not to be, but the TFA really helps. At the beginning of the year, my confidence was at a 2 [out of 10] because I knew a limited amount of stuff about concepts, but learning new concepts was really hard because it wasn't really working for me. And now it is like a 10 with the TFA. I was really bad at the beginning of the year writing scientific explanations. I didn't really have words I could use to explain it without drawing something but the TFA has helped me a lot as well because it's just structured better for me to write down scientific explanations. Beginning it was about 1 [out of 10] and at the end it was about 9 or 10. [My interest in Science] has really improved. Like at the start I 
was OK with doing science. And then with the TFA learning about interesting things that I wouldn't really have thought about and I want to know. Interest at the beginning was about a 3 or 4 and now it is about a 10 because I am way more interested.

\section{Changes in Student Confidence in Writing Scientific Explanations}

In interviews at the end of the year, 19 of the 27 students interviewed described much greater confidence in writing scientific explanations after learning with the TFA. Four students noted that they had more confidence in knowing how to use scientific vocabulary correctly, while seven students said that practice forming explanations multiple times in different modes (verbal, pictorial, written) within a given TFA lesson gave greater fluency and confidence in producing written explanations. Students identified a number of aspects of the TFA which supported them in constructing understanding of the phenomena and this in turn, supported their ability to write causal explanations: use of multiple representations $(n=21)$, scaffolding of explanation construction $(n=14)$, gradual development of understanding of the theoretical model $(n=19)$, co-construction and peer support within small groups $(n=21)$, and feedback $(n=21)$ (McLure et al., 2020c).

\section{Discussion}

Evidence presented in this study suggests that using the TFA provides teachers with a way forward for explicitly supporting students in writing elaborated causal explanations of scientific phenomena. While eight students (17\%) gave non-explanations and 23 students $(50 \%)$ simply described the key observations related to the guiding question without addressing the underlying causes in the first lesson, by the end of the 14th TFA lesson, no students gave non-explanations and only four students $(9 \%)$ gave descriptions of the phenomena (Fig. 2). Students' initial difficulties identifying the most relevant aspects of a phenomenon is consistent with studies of students' written explanations of Faria et al. (2014). Participating in the TFA enabled students to identify the key observations which were directly related to the guiding question.

Similar to the study of Taber and Garcia-Franco (2010), students in this study initially had difficulty relating observations to underlying scientific models (c.f. Jimenez-Aleixandre et al., 2000; McNeill et al., 2006) and using non-visible processes and entities in their explanations (Prain et al., 2009). In the first lesson, only 10 students (22\%) gave associative explanations without elaboration or complete chains of reasoning and five students (11\%) produced one simple causal chain of reasoning. However, by the end of the teaching period, 32 students $(91 \%)$ were able to produce a causal explanation at an associative, simple, or complex level (Fig. 2). Furthermore, while no students were initially able to produce complex scientific explanations, 10 students (22\%) were producing complex causal explanations after learning with the TFA.

The benefit to students was further highlighted by a comparison made between students in the TFA group and a non-treatment class who were asked to write a scientific explanation under exam conditions. Sixty-six percent of students who had learned to write elaborated causal explanations using the TFA were independently able to produce causal explanations at an associative level or higher compared to $28 \%$ of students in the 
comparison class who had not experienced the support of the TFA to write explanations (Fig. 3).

The evidence indicates that the TFA provided explicit scaffolding for students to develop causal written explanations, the need for which was suggested by McNeill et al. (2006) and Osborne et al. (2004). This resulted in a significant improvement in students' engagement with theoretical scientific concepts such as specific heat capacity and latent heat of vaporisation, and successful use of non-visible entities and processes such as energy transfer between particles through collisions and changes in density due to those collisions.

As noted in a prior study utilising the affordances of student-generated diagrams to explain phenomena (McLure et al., 2021), students who engaged with producing both verbal and pictorial representations of their explanations were more likely to integrate sub-microscopic and non-visible entities into those explanations. As students produced multiple representations of their explanations (verbally through co-construction of understanding with peers, through drawing and summary dot-points, culminating in an elaborated written explanation), they were able to build more complex chains of reasoning. Socratic questioning drew students' attention to underlying theoretical models, and self-evaluation using the LM rubric encouraged greater self-regulation. As students received feedback about the level of their writing, they also became more aware of the elements that make up causal explanations and further engaged with the co-construction process (McLure et al., 2020a). Gains in both conceptual understanding, as evidenced by improved outcomes on conceptual tests (McLure et al., 2020c, d) and in written explanation levels, resulted in students' increased confidence in their ability to write causal explanations. Tests of conceptual understanding and student results based on other assessment strategies indicated that students were performing at or above the expected achievement standards for their age group (ACARA, 2016a). The increase in confidence in understanding new scientific concepts and writing explanations is detailed in a longitudinal study of the TFA (McLure et al., 2020c) and a case study of one student's experience (McLure et al., 2020a).

\section{Limitations and Future Research}

This study was carried out in two classrooms with relatively small groups of students. Although the results were replicated in the following year, further studies of the effects of the TFA as a support for developing students' written explanations with larger cohorts would provide further evidence for the benefits of this approach. Additionally, the benefits of the TFA as a structured approach for supporting other teachers in developing students' written explanations would further validate the transferability of this approach. It was beyond the scope of this study to investigate what other writing improvement programs students may have been engaged in, for instance in English lessons, during the period of this study. However, since students in the comparison group would also have been engaged in similar programs, the higher degree of improvement observed in the TFA group indicates that the TFA has benefits for written explanations beyond those conferred by participation in more generalised writing programs. 


\section{Conclusion}

This longitudinal study of implementation of the TFA to support students in writing scientific explanations showed that, while the majority $(>50 \%)$ of students began the year by writing non-explanations or descriptions rather than causal explanations, more than $90 \%$ of students were able to write causal scientific explanations of scientific phenomena after learning with the TFA over a nine-month period. Additionally, students became more confident in identifying the key observational aspects that should be included in explanations and making links between theoretical scientific concepts, non-visible entities and processes and their observations.

Funding Open Access funding enabled and organized by CAUL and its Member Institutions.

\section{Declarations}

Conflicts of Interest The author declares no competing interests.

Open Access This article is licensed under a Creative Commons Attribution 4.0 International License, which permits use, sharing, adaptation, distribution and reproduction in any medium or format, as long as you give appropriate credit to the original author(s) and the source, provide a link to the Creative Commons licence, and indicate if changes were made. The images or other third party material in this article are included in the article's Creative Commons licence, unless indicated otherwise in a credit line to the material. If material is not included in the article's Creative Commons licence and your intended use is not permitted by statutory regulation or exceeds the permitted use, you will need to obtain permission directly from the copyright holder. To view a copy of this licence, visit http://creativecommons.org/licenses/by/4.0/.

\section{References}

ACARA. (2016a). Literacy. Retrieved from https://www.australiancurriculum.edu.au/f-10-curriculum/ general-capabilities/literacy/

ACARA. (2016b). Science sequence of achievement: 7-10. Retrieved from https://www.australiancurri culum.edu.au/f-10-curriculum/science/content-and-achievement-sequences/

Braaten, M., \& Windschitl, M. (2011). Working toward a stronger conceptualization of scientific explanation for science education. Science Education, 95(4), 639-669. Retrieved from https://onlinelibrary.wiley.com/doi/abs/https://doi.org/10.1002/sce.20449

Brigandt, I. (2016). Why the difference between explanation and argument matters to science education. Science \& Education, 25(3-4), 251-275. https://doi.org/10.1007/s11191-016-9826-6

Chang, C.-J., Liu, C.-C., \& Tsai, C.-C. (2016). Supporting scientific explanations with drawings and narratives on tablet computers: An analysis of explanation patterns. The Asia-Pacific Education Researcher, 25(1), 173-184. https://doi.org/10.1007/s40299-015-0247-0

Chi, M. T. H. (1992). Conceptual change within and across ontological categories: Examples from learning and discovery in science. In R. N. Giere (Ed.), Minnesota studies in the philosophy of science: Cognitive models of science (Vol. XV, pp. 129-186). University of Minnesota Press.

Council of Ministers of Education, Canada. (2013). Pan-Canadian assessment program: Science assessment framework.

Creswell, J. W. (2014). Research design: Qualitative, quantitative and mixed methods approaches. Sage.

de Andrade, V., Freire, S., \& Baptista, M. (2019). Constructing scientific explanations: A system of analysis for students' explanations. Research in Science Education, 49, 787-807. https://doi.org/10. 1007/s11165-017-9648-9

Duit, R., \& Treagust, D. F. (1998). Learning in science: From behaviourism towards social constructivism and beyond. In B. J. Fraser \& K. G. Tobin (Eds.), International handbook of science education, Part 1 (pp. 3-25). Kluwer Academic Publishers. 
Duit, R., \& Treagust, D. F. (2012). How can conceptual change contribute to theory and practice in science education? In B. J. Fraser, K. G. Tobin, \& C. J. McRobbie (Eds.), Second international handbook of science education (pp. 107-118). Springer.

Faria, C., Freire, S., Baptista, M., \& Galvao, C. (2014). The construction of a reasoned explanation of a health phenomenon: An analysis of competencies mobilized. International Journal of Science Education, 36(9), 1476-1490.

Fensham, P. J., \& Bellocchi, A. (2013). Higher order thinking in chemistry curriculum and its assessment. Thinking Skills and Creativity, 10(1), 250-264. https://doi.org/10.1016/j.tsc.2013.06.003

Friedman, M. (1974). Explanation and scientific understanding. Journal of Philosophy, 71, 5-19.

Gilbert, J. K., Boulter, C. J., \& Rutherford, M. (2000). Explanations with models in science education. In J. K. Gilbert \& C. J. Boulter (Eds.), Developing models in science education (pp. 193-208). Kluwer.

Gilbert, J. K., \& Treagust, D. F. (2009). Introduction: Macro, submicro and symbolic representations and the relationship between them: Key models in chemical education. In J. K. Gilbert \& D. F, Treagust (Eds.), Multiple representations in chemical education (pp. 1-8). Netherlands:Springer.

Hattie, J., \& Timperley, H. (2007). The power of feedback. Review of Educational Research, 77(1), $81-112$.

Hsu, C.-C., Chiu, C.-H., Lin, C.-H., \& Wang, T.-I. (2015). Enhancing skill in constructing scientific explanations using a structured argumentation scaffold in scientific inquiry. Computers \& Education, 91, 46-59. https://doi.org/10.1016/j.compedu.2015.09.009

Jimenez-Aleixandre, M. P., Rodriguez, A. B., \& Duschl, R. A. (2000). "Doing the lesson" or "doing science": Argument in high school genetics. Science Education, 84, 757-792.

Kitcher, P. (1989). Explanatory unification and the causal structure of the world. In P. Kitcher \& W. C. Salmon (Eds.), Minnesota studies in the philosophy of science: Vol. XIII. Scientific explanation. Minneapolis: University of Minnesota Press.

McLure, F. (2020). The Thinking Frames Approach: A case study of inclusion using student-generated multiple representations. Journal of Research in Special Educational Needs, 20(1), 3-13. https:// doi.org/10.1111/1471-3802.12456

McLure, F., Won, M., \& Treagust, D. F. (2020a). 'Even though it might take me a while, in the end, I understand it': a longitudinal case study of interactions between a conceptual change strategy and student motivation, interest and confidence. Disciplinary and Interdisciplinary Science Education Research, 2(10). https://doi.org/10.1186/s43031-020-00027

McLure, F., Won, M., \& Treagust, D. F. (2020b). Students' understanding of the emergent processes of natural selection: The need for ontological conceptual change. International Journal of Science Education, 42(9), 1485-1502. https://doi.org/10.1080/09500693.2020.1767315

McLure, F., Won, M., \& Treagust, D. F. (2020c). A sustained multidimensional conceptual change intervention in grade 9 and 10 science classes. International Journal of Science Education, 42(5), 703721. https://doi.org/10.1080/09500693.2020.1725174

McLure, F., Won, M., \& Treagust, D. F. (2020d). Teaching thermal physics to Year 9 students: the thinking frames approach. Physics Education, 55(3), 035007. https://doi.org/10.1088/1361-6552/ab6c3c

McLure, F., Won, W., \& Treagust, D. F. (2021). Analysis of students' diagrams explaining scientific phenomena. Research in Science Education. https://doi.org/10.1007/s11165-021-10004-y

McNeill, K. L., Lizotte, D. J., Krajcik, J., \& Marx, R. W. (2006). Supporting students' construction of scientific explanations by fading scaffolds in instructional materials. Journal of the Learning Sciences, 15(2), 153-191.

National Research Council. (2012). A framework for K-12 science education: Practices, crosscutting concepts, and core ideas. National Academies Press Retrieved from https://www.nap.edu/catalog/ 13165/a-framework-for-k-12-science-educationpractices-crosscutting-concepts.

Nawani, J., von Kotzebue, L., Spangler, M., \& Neuhaus, B. J. (2019). Engaging students in constructing scientific explanations in biology classrooms: A lesson-design model. Journal of Biological Eductation, 53(4), 378-389. https://doi.org/10.1080/00219266.2018.1472131

Newberry, M., Gilbert, J. K., \& Cams Hill Science Consortium (2011). The thinking frames approach. Primary Science Teaching Trust. Retrieved from https://pstt.org.uk/resources/cpd-units/the-think ing-frames-approach

Newberry, M., Gilbert, J. K., \& Hardcastle, D. (2005). Visualising progression through the science curriculum in order to raise standards. School Science Review, 86(316), 87-96.

Osborne, J., Erduran, S., \& Simon, S. (2004). Enhancing the quality of argumentation in school science. Journal of Research in Science Teaching, 41, 994-1020.

Osborne, J., \& Patterson, A. (2011). Scientific argument and explanation: A necessary distinction? Science Education, 95, 627-638. 
Posner, G. J., Strike, K. A., Hewson, P. W., \& Gertzog, W. A. (1982). Accommodation of a scientific conception: Towards a theory of conceptual change. Science Education, 66, 211-227.

Prain, V., Tytler, R., \& Peterson, S. (2009). Multiple representation in learning about evaporation. International Journal of Science Education, 31(6), 787-808.

Salmon, W. C. (1984). Scientific explanation and the causal structure of the world. Princeton University Press.

Sinatra, G. M., \& Pintrich, P. (2003). The role of intentions in conceptual change learning. In G. M. Sinatra \& P. Pintrich (Eds.), Intentional conceptual change (pp. 1-18). Lawrence Erlbaum Associates.

Taber, K. S., \& Garcia-Franco, A. (2010). Learning processes in chemistry: Drawing upon cognitive resources to learn about the particulate structure of matter. Journal of Learning Sciences, 19(1), 99-142.

Tang, K.-S. (2016). Constructing scientific explanations through premise-reasoning-outcome (PRO): An exploratory study to scaffold students in structuring written explanations. International Journal of Science Education, 38(9), 1-26. https://doi.org/10.1080/09500693.2016.1192309

Treagust, D. F., Won, M., \& McLure, F. (2018). Multiple representations and students' conceptual change in science. In T. Amin \& O. Levrini (Eds.), Converging and complementary perspectives on conceptual change (pp. 121-128). Routledge.

Vosniadou, S. (1994). Capturing and modeling the process of conceptual change. Learning and Instruction, 4(1), 45-69.

Woodward, J. (2003). Making things happen: A theory of causal explanation. Oxford University Press.

Yang, H.-T., \& Wang, K.-H. (2014). A teaching model for scaffolding 4th grade students' scientific explanation writing. Research in Science Education, 44(4), 531-548. https://doi.org/10.1007/ s11165-013-9392-8

Yin, R. K. (2009). Case study research: Design and methods (4th ed. Vol. 5). Thousand Oaks, California: SAGE.

Zimmerman, C. (2007). The development of scientific thinking skills in elementary and middle school. Developmental Review, 27(2), 172-223. https://doi.org/10.1016/j.dr.2006.12.001

Publisher's Note Springer Nature remains neutral with regard to jurisdictional claims in published maps and institutional affiliations. 